\title{
STUDI KEANEKARAGAMAN JENIS BURUNG DI KAWASAN HUTAN KOTA DESA KUWIL KABUPATEN MINAHASA UTARA
}

\author{
Rio Priyanto Saibi ${ }^{1)}$, Saroyo ${ }^{1)}$, Hanny Hesky Pontororing ${ }^{1)}$ \\ ${ }^{1)}$ Program Studi Biologi FMIPA UNSRAT Manado, 95115
}

\begin{abstract}
Birds are one of the forest's ecosystem components which able to help in the forest's natural regeneration, with one of the bird's natural habitats being urban forests. This study aims to analyze the diversity and describe the bird's species in the Urban Forest habitat of the Kuwil Village of North Minahasa Regency. Data collection used survey methods with plots in form of 2 rectangular line transects with a length of $2000 \mathrm{~m}$ each and $20 \mathrm{~m}$ wide. Data collection is done 5 times. Based on the research, there were 10 species of birds with a diversity index of bird species as 1.98 which was in the medium category. The species found were Halcyon chloris, Corvus enca, Pycnonotus aurigaster, Oriolus chinensis, Gerygone sulphurea, Galliralus torquatus, Phaenicophaeus calyorhynchus, Eudynamys melanorhyncus, Geopelia striata, and Ducula aenea.
\end{abstract}

Key words: Species Diversity, Urban Forest, Bird

\begin{abstract}
ABSTRAK
Burung merupakan salah satu komponen ekosistem hutan dengan fungsinya membantu regenerasi hutan secara alami, dengan salah satu habitat alami burung adalah hutan kota. Penelitian ini bertujuan untuk menganalisis keanekaragaman jenis burung pada habitat Hutan Kota Desa Kuwil Kabupaten Minahasa Utara dan mendeskripsikan jenis-jenisnya. Pengambilan data menggunakan metode survei dengan plot berbentuk 2 garis transek (line transect) persegi panjang dengan panjang masing-masing transek $2000 \mathrm{~m}$ dan lebar $20 \mathrm{~m}$. Pengambilan data dilakukan sebanyak 5 kali. Berdasarkan penelitian didapatkan 10 jenis burung dengan nilai indeks keanekaragaman jenis burung sebesar 1,98 yang termasuk kategori sedang. Adapun jenis-jenis burung yang ditemukan adalah sebagai berikut Halcyon chloris, Corvus enca, Pycnonotus aurigaster, Oriolus chinensis, Gerygone sulphurea, Galliralus torquatus, Phaenicophaeus calyorhynchus, Eudynamys melanorhyncus, Geopelia striata dan Ducula aenea.
\end{abstract}

Kata kunci: Keanekaragaman Jenis, Hutan Kota, Burung 


\section{PENDAHULUAN}

Indonesia merupakan negara yang kaya akan keanekaragaman jenis sehingga banyak ilmuwan biologi dari bidang biodiversitas dan konservasi terus melakukan penelitian tentang jenis hewan yang ada. Salah satu hewan yang memiliki banyak jenis yaitu burung. Burung pada setiap jenisnya memiliki perbedaan dari bentuk anggota tubuhnya seperti paruh, makanan, perilaku dan suaranya.

Menurut Sukmantoro et al. (2007), Indonesia memiliki 1598 spesies burung atau sekitar 17 persen dari total jenis burung di dunia. Pulau-pulaunya merupakan rumah bagi sepertiga lebih spesies burung langka Asia. Pulau di Indonesia yang memiliki keanekaragaman jenis burung salah satu di antaranya yaitu Sulawesi karena terletak di kawasan wallacea yang merupakan wilayah transisi diantara batas benua Asia dan Australia. Keunikan flora dan fauna dalam wilayah transisi ini, menyebabkan evolusi dari banyak spesies yang unik. Sulawesi bagian utara terdapat 13 spesies burung endemik dari 89 spesies burung endemik Sulawesi (15\%) (Lee, et al., 2001).

Burung merupakan salah satu komponen dalam ekosistem kehidupan terutama hutan. Burung berperan penting dalam membantu regenerasi hutan secara alami seperti penyebar biji, penyerbuk bunga dan pengontrol hama (Oktiana dan Antono, 2015). Keberadaan jenis burung di hutan tergantung kemampuan adaptasi pada kondisi lingkungan yang ada sebagai penyedia makanan, sebagai rumah atau tempat berlindung tanpa ada gangguan, ada terjadi interaksi antara jenis satwa lain yang saling mempengaruhi satu sama lainnya dan membentuk ekosistem yang kompleks. Burung-burung liar nampak terlihat indah dan dinikmati oleh masyarakat karena keindahan bulu dan suaranya, dari burung liar dapat mengenalkan masyarakat tentang konservasi serta kesadaran akan lingkungan dan nilai kekayaan burung untuk dimanfaatkan sebaikbaiknya.

Namun karena terjadi aktivitas manusia yang mengakibatkan berkurangnya diversitas flora dan fauna seperti penebangan hutan, perburuan satwa, pencemaran dan kebakaran hutan, sehingga menyebabkan berkurangnya populasi satwa. Pada saat ini populasi burung sangat menurun, karena mengalami gangguan dari berbagai faktor antara lain kerusakan habitat, perburuan liar, dan kurangnya kesadaran masyarakat akan arti pentingnya kelestarian alam dan lingkungan (Boer, 1994). Akibat dari adanya gangguan-gangguan tersebut maka burung akan berpindah tempat untuk mencari habitat yang cocok untuknya .

Salah satu habitat alami burung ialah hutan kota. Hutan ini memiliki tipe vegetasi terutama sekunder, walaupun tetap menunjukkan ciri hutan primer. Contoh hutan kota yang menjadi habitat burung ialah Hutan Kota Desa Kuwil di Kecamatan Kalawat, Kabupaten Minahasa Utara. Hutan kota yang terdapat di Desa Kuwil Kecamatan Kalawat Kabupaten Minahasa Utara merupakan bagian Ruang Terbuka Hijau (RTH) wilayah perkotaan yang ditetapkan pada tahun 2012 oleh Pemerintah Kabupaten, dengan luas areal hutan \pm 43 Ha (Dinas Kehutanan, 2013).

Penelitian ini bertujuan untuk menganalisis keanekaragaman jenis burung pada habitat Hutan Kota Desa Kuwil Kabupaten Minahasa Utara dan mendeskripsikan jenis-jenisnya. Sampai saat ini, penelitian tentang keanekaragaman jenis burung di hutan kota ini belum pernah dilakukan. Oleh karena itu, survei tentang keanekaragaman jenis burung di lokasi ini penting untuk dilakukan mengingat pentingnya informasi tentang keanekaragaman burung dan manfaat burung bagi ekosistem. 


\section{METODOLOGI PENELITIAN}

\section{Waktu dan Tempat Penelitian}

Penelitian telah dilaksanakan pada bulan Maret 2019 sampai dengan bulan April 2019 di kawasan Hutan Kota Desa Kuwil Kabupaten Minahasa Utara.

\section{Prosedur Penelitian}

Prosedur pengambilan data dalam penelitian ini adalah menggunakan metode survei dengan plot berbentuk transek garis (line transect). Metode survei dilakukan dengan cara membentuk beberapa plot transek persegi panjang, dengan plot 2 garis transek dengan panjang $2000 \mathrm{~m}$ dan lebar $20 \mathrm{~m}$ berjalan menelusuri jalur pengamatan. Pengamatan burung dilakukan dengan mengikuti garis transek sebanyak 5 kali dan berjalan menelusuri jalur yang telah diberi garis transek kemudian mencatat tiap jenis burung yang ditemukan di dalam area tersebut. Burung-burung yang diamati hanya yang berjarak maksimal $50 \mathrm{~m}$ dari garis transek dengan posisi tegak lurus.

Pengumpulan data jenis burung pada tiap plot dilaksanakan dari jam 06.00-10.00 WITA dengan kecepatan jalan $1 \mathrm{~km} / \mathrm{jam}$. Pengamatan burung meliputi waktu, jenis burung, jumlah burung, dan aktivitas burung yang dilakukan. Menurut Bibby et al. (2000), Setiap burung yang dijumpai dicatat jenisnya, waktu dan nama lokasi, perkiraan jarak pengamat pada burung, tipe aktivitas, serta kondisi sekitar.

Untuk menentukan jenis-jenis burung dilakukan identifikasi berdasarkan ciri-ciri morfologi dengan menggunakan buku identifikasi yang berjudul Panduan Lapangan Burung-Burung di Kawasan Wallacea karangan Brian J. Coates dan David Bishop, 1997. Menurut Coates dan Bishop (1997), ciri-ciri morfologi yang digunakan dalam identifikasi meliputi paruh, sayap, warna bulu, tungkai dan ekor.

\section{HASIL DAN PEMBAHASAN}

Tabel 1. Densitas Jenis Burung

\begin{tabular}{llllll}
\hline \multirow{2}{*}{ No Jenis } & \multicolumn{2}{l}{ Setiap Lokasi } & \multicolumn{2}{c}{ D } \\
& & $\mathrm{T} 1$ & $\mathrm{~T} 2$ & $\mathrm{~N}$ & Ekor/Km2 \\
\hline 1 & Halcyon chloris & 8 & 11 & 19 & 47,5 \\
2 & Gerygone sulphurea & 6 & 0 & 6 & 15 \\
3 & Oriolus chinensis & 8 & 0 & 8 & 20 \\
4 & Pycnonotus aurigaster & 16 & 26 & 42 & 105 \\
5 & Gallirallus torquatus & 6 & 10 & 16 & 40 \\
6 & Corvus enca & 11 & 19 & 30 & 75 \\
7 & Phaenicophaeus calyorhynchus & 1 & 1 & 2 & 5 \\
8 & Eudynamys melanorhynchus & 2 & 2 & 4 & 10 \\
9 & Ducula aenea & 0 & 10 & 10 & 25 \\
10 & Geopelia striata & 5 & 0 & 5 & 12,5 \\
\hline & Total & 63 & 79 & 142 & 355 \\
\hline
\end{tabular}


Tabel 2. Indeks Keanekaragaman Jenis Burung

\begin{tabular}{lllllll}
\hline No & Jenis & $\mathrm{N}$ & $\mathrm{Pi}$ & Lnpi & Pi.Lnpi & H' $^{\prime}$ \\
\hline 1 & Halcyon chloris & 19 & 0,13 & $-2,04$ & $-0,27$ & \\
2 & Gerygone sulphurea & 6 & 0,04 & $-3,22$ & $-0,13$ & \\
3 & Oriolus chinensis & 8 & 0,06 & $-2,81$ & $-0,17$ & \\
4 & Pycnonotus aurigaster & 42 & 0,30 & $-1,20$ & $-0,36$ & \\
5 & Gallirallus torquatus & 16 & 0,11 & $-2,21$ & $-0,24$ & \\
6 & Corvus enca & 30 & 0,21 & $-1,56$ & $-0,33$ & \\
7 & Phaenicophaeus calyorhynchus & 2 & 0,01 & $-4,61$ & $-0,05$ & \\
8 & Eudynamys melanorhynchus & 4 & 0,03 & $-3,51$ & $-0,11$ & \\
9 & Ducula aenea & 10 & 0,07 & $-2,66$ & $-0,19$ & \\
10 & Geopelia striata & 5 & 0,04 & $-3,22$ & $-0,13$ & \\
\hline & Total & 142 & 1,00 & 0,00 & $-1,98$ & 1,98 \\
\hline
\end{tabular}

Hasil penelitian yang telah dilakukan di kawasan Hutan Kota Desa Kuwil Kabupaten Minahasa Utara (Tabel1) Kelimpahan total dari setiap jenis burung yaitu 142 individu dengan kepadatan rata-rata total 355 ekor $/ \mathrm{Km}^{2}$. Jenis burung yang kelimpahannya paling tinggi yaitu Pycnonotus aurigaster 42 individu dengan kepadatan paling tinggi yaitu 105 ekor $/ \mathrm{km}^{2}$. Jenis burung dengan kelimpahan paling rendah yaitu Phaenicophaeus calyorhynchus 2 individu yang kepadatannya juga rendah 5 ekor $/ \mathrm{km}^{2}$. Jumlah jenis burung yang ditemukan dari semua lokasi penelitian yaitu sebanyak 10 jenis dengan indeks keanekaragaman burung sebesar 1,98 (tabel 2) yang termasuk dalam kategori keanekaragaman spesies sedang $\left(1,5 \leq \mathrm{H}^{\prime} \leq\right.$ 3,5). Hal ini berarti kondisi lingkungan hutan kota cukup baik untuk kehidupan jenis burung yang mana terjadi produktivitas jenis burung dengan sebaran atau distribusi cukup merata. Aktivitas manusia yang jarang disana sehingga memungkinkan beragam jenis burung hidup tanpa terganggu. Alikodra (1990) menyatakan bahwa kondisi lingkungan, jumlah jenis dan sebaran individu pada masing-masing jenis adalah faktor yang mempengaruhi nilai keanekaragaman jenis $\left(\mathrm{H}^{\prime}\right)$.

Membandingkan dengan penelitian Tallei et al. (2018) mengenai diversitas jenis burung liar di kawasan Taman Hutan Raya Gunung Tumpa Sulawesi Utara Indonesia, ditemukan 33 jenis burung dengan nilai indeks keanekaragaman (H') 2,94 yang menunjukkan tingkat keanekaragaman jenis sama-sama sedang. Penelitian Patandung et al. (2013) yang meneliti tentang struktur dan komposisi jenis komunitas burung di lahan pertanian kawasan Hutan Lindung Gunung Mahawu Sulawesi Utara. Hasil penelitiannya yaitu terdapat 32 jenis burung dari 16 famili dan 9 ordo, dengan jumlah individu 45 dan nilai indeks keanekaragaman 2,92 termasuk kategori sedang. Lokasi yang sama penelitian dilakukan Kindangen (2006) meneliti tentang keanekaragaman jenis burung diurnal di kawasan Hutan Lindung Gunung Mahawu ditemukan 31 jenis burung diurnal dengan nilai indeks keanekaragaman 2,59 yang termasuk kategori sedang. Menurut Tallei et al. (2018) hutan yang memiliki tingkat keanekaragaman jenis sedang memiliki produktivitas yang cukup, kondisi ekosistem yang seimbang, serta tekanan ekologis yang sedang. Nilai indeks keanekaragaman (H') 
pada umumnya hanya antara 1,5 dan 3,5 dalam sebagian penelitian bidang ekologi, dan jarang nilai indeks keanekaragaman $\left(\mathrm{H}^{\prime}\right)$ lebih besar dari 4.

Perbedaan jumlah jenis burung dari ketiga lokasi penelitian disebabkan Taman Hutan Raya Gunung Tumpa dan Hutan Lindung Gunung Mahawu merupakan daerah konservasi sehingga pengawasan terhadap hutan ini lebih ketat sehingga aktivitas manusia lebih dibatasi, dibandingkan dengan Hutan Kota Desa Kuwil meskipun berstatus hutan lindung, tetapi kurangnya pengawasan, luas hutan yang kecil, dan dekat daerah pembangunan lahan, sehingga jenis-jenis burung yang ditemukan di kawasan Hutan Kota Desa Kuwil lebih sedikit daripada yang ditemukan di Taman Hutan Raya Gunung Tumpa dan Hutan Lindung Gunung Mahawu. Hutan kota ini dipengaruhi oleh kondisi lingkungan yang mana komposisi tumbuhan untuk menyusun vegetasi pada kawasan ini bersifat heterogen. Ekowati et al. (2016) menyatakan tipe vegetasi yang heterogen menjadikan kawasan hutan habitat yang baik bagi jenis-jenis satwa termasuk burung, karena tersedianya kebutuhan hidup burung seperti pakan, tempat bersarang dan beraktifitas. Kondisi hutan kota yang jauh dari gangguan manusia, serta tersedianya pakan yang cukup, memungkinkan memiliki jenis burung yang banyak (Widodo, 2009).

Deskripsi jenis-jenis burung yang ditemukan di kawasan Hutan Kota Desa Kuwil Kabupaten Minahasa Utara adalah sebagai berikut.

\section{Halcyon chloris (Cekakak Sungai)}

Saat ditemukan memiliki tubuh cukup besar dengan panjang 24-26,5 cm, serta memiliki mahkota dan bagian atas biru atau hitam hingga hijau biru, warna bulu hijau biru kerah leher belakang dengan bagian bawah putih, memiliki paruh yang kokoh dan tengkuk sering kelihatan bercak keputihputihan (Coates dan Bishop,1997). Sebagian besar bertempat di hutan sekunder, hutan pesisir, pedesaan terbuka yang pohonnya banyak, perkotaan, hutan rawa, rawa-rawa, perkebunan kelapa, tepi hutan, dan pulaupulau kecil. Jenis burung ini mampu hidup sampai ketinggian 730-2000 mdpl. Penyebarannya hampir di seluruh kawasan wallacea (Coates dan Bishop,1997). Aktivitas yang dilakukan Halcyon chloris selama penelitian ialah terbang, bertengger pada salah satu pohon dan bersuara. Jenis burung ini mencari makan pada pepohonan yang jarang serta pada daerah rawa dan sungai. Burung ini pemakan serangga maupun ikan di sungai dan bersarang pada pohon yang tinggi.

\section{Gerygone sulphurea (Remetuk Laut)}

Burung Remetuk Laut saat ditemukan memiliki punggung berwarna coklat zaitun keabu-abuan, mahkota abu-abu bagian leher sampai perut berwarna kuning, bulu serta ekor luar berwarna putih (Coates dan Bishop, 1997). Burung ini biasanya terdapat di perkebunan, sebagian besar di pesisir, mangrove, hutan pegunungan dan hutan sekunder, tapi juga meluas sampai dataran tinggi, dari permukaan laut hingga $2300 \mathrm{mdpl}$ (Coates dan Bishop, 1997). Aktivitas yang dilakukan selama pengamatan seperti berpindah-pindah dari satu pohon ke pohon lain, terbang, bertengger, dan mencari makan. Burung ini ditemukan hanya di transek 1 dengan kelimpahan 6 individu, hal ini dikarenakan transek 1 memiliki lebih banyak tumbuhan berbunga daripada transek 1 dengan mencari makan di semak berbunga, dan pohon yang berbuah untuk mencari makanan berupa serangga atau ulat kecil.

\section{Oriolus chinensis (Kepudang Kuduk- Hitam)}


Burung Kepudang Kuduk-Hitam saat ditemukan berukuran relatif sedang, panjang mulai ujung ekor hingga paruh, bulunya berwarna kuning, terdapat garis hitam pada matanya dan tubuhnya. Menurut Del Hoyo dan Collar (2016) ukuran burung ini berkisar 25-26 cm, Bulunya berwarna kuning keemasan, bagian kepala,sayap dan ekor ada sebagian bulu yang berwarna hitam. Garis hitam melewati mata dan tengkuk, bentuk paruh meruncing dan sedikit melengkung ke bawah. Jenis burung ini menghuni umumnya menghuni habitat yang pohonnya terbanyak, seperti hutan sekunder atau primer yang tinggi, tetapi ada juga di pedesaan dan perkotaan. Hasil penelitian Wantania (2010) tentang analisis keragaman burung di Gunung Klabat, burung ini ditemukan di hutan sekunder Gunung Klabat. Jenis ini hidup sampai ketinggian 850-1500 mdpl, penyebarannya hampir seluruh kawasan wallacea (Coates dan Bishop, 1997). Aktivitas burung Kepudang Kuduk-Hitam selama pengamatan yaitu terbang dan bertengger di satu pohon ke pohon lain untuk mencari makan. Burung ini ditemukan hanya di lokasi transek 1 dengan jumlah kelimpahan 6 individu. Hal ini dikarenakan burung ini lebih menyukai tumbuhan yang berbunga dan berbuah untuk mencari serangga yang ada. Pada lokasi transek 1 terdapat lebih banyak tumbuhan berbunga dan berbuah. Menurut Coates dan Bishop (1997) Kebun buah dan pohon hortikultura yang dikelilingi merupakan tempat mencari makan terbaik karena pepohonan cenderung menarik serangga.

\section{Phaenicophaeus calyorhynchus (Kadalan Sulawesi)}

Burung Kadalan Sulawesi saat ditemukan memiliki panjang tubuh sekitar 51$53 \mathrm{~cm}$. Paruhnya tebal dan kokoh, dengan paruh atas berwarna kuning dan menghitam pada bagian ujung, paruh yang bawah berwarna merah dan ekor panjang berwarna biru gelap (Coates dan Bishop, 1997). Burung Kadalan Sulawesi sebagian besar menghuni hutan primer dan sekunder. Jenis ini juga biasa ditemukan di tepi hutan dan lahan pertanian. Dari permukaan laut burung ini mampu hidup sampai ketinggian $1650 \mathrm{~m}$ (Coates dan Bishop, 1997). Aktivitas jenis burung ini pada saat pengamatan yaitu terbang dan bertengger pada salah satu pohon, saat didekati burung ini akan terbang ke tempat yang lain dan sulit untuk mendapatkan fotonya. Makanan utama burung ini adalah serangga.

\section{Pycnonotus aurigaster (Cucak Kutilang)}

Burung Cucak Kutilang saat ditemukan berukuran sedang, dengan panjang tubuh sekitar $20 \mathrm{~cm}$. Sisi bagian atas tubuh (punggung dan ekor) berwarna coklat kelabu, pada sisi bawah (tenggorokan, leher, dada, dan perut) berwarna putih keabu-abuan. Memiliki topi, dahi, dan jambul berwarna hitam, tunggir (bagian muka ekor) berwarna putih, serta penutup pantat berwarna kuning jingga (Coates dan Bishop, 1997). Jenis burung ini tersebar meliputi hampir semua habitat mulai dari pepohonan terbuka, tepi hutan, semak belukar, hutan sekunder, tepi jalan, pekarangan, kebun, hingga tamantaman di perkotaan. Umumnya tersebar mulai dari dataran rendah sampai ketinggian 1.500 mdpl (Coates dan Bishop, 1997). Aktivitas burung cucak kutilang selama pengamatan yaitu terbang, bersuara, bertengger dan makan. Pada setiap transek burung ini mendominasi dari setiap jenis burung yang ditemukan. Burung Kutilang biasanya sering terlihat berkumpul bersama di perkebunan, pohon-pohon tinggi untuk mencari makanan, yaitu buah-buahan yang lunak dan serangga kecil. 


\section{Eudynamys melanorhynchus (Tuwur Sulawesi)}

Tuwur Sulawesi memiliki panjang tubuh sekitar $36-44 \mathrm{~cm}$ dengan ekor panjang membulat, paruh berwarna hitam, dan mata berwarna merah (Coates dan Bishop, 1997) Burung ini umum secara lokal, menghuni hutan primer dan sekunder yang tinggi, hutan di tepi sungai, serta daerah yang sedikit pohon di dataran rendah. Burung ini mampu hidup sampai ketinggian $1590 \mathrm{mdpl}$. Aktivitas burung Tuwur Sulawesi saat pengamatan yaitu berpindah, terbang dan lebih sering bersuara, sifatnya pemalu sehingga jika didekati akan terbang ke tempat yang lain dan sulit untuk mendapatkan fotonya. Burung ini termasuk tipe pemakan buah-buahan sebagai makanan utamanya.

\section{Corvus enca (Gagak Hutan)}

Gagak Hutan saat ditemukan memiliki tubuh dengan ukuran besar 34-45 cm. Berwarna hitam, Paruh ukuran besar. Terbang dengan kepakan pendek-pendek. Iris coklat, paruh hitam, dan kaki hitam (Coates and bishop, 1997). Habitatnya sebagian besar menghuni pesisir, dataran rendah, hutan primer dan sekunder, suka bertengger di ranting pada pohon besar dan ketinggian. Jenis ini mampu hidup dari permukaan laut sampai ketinggian $1600 \mathrm{~m}$ (Coates and Bishop, 1997). Aktivitas yang dilakukan oleh burung gagak hutan selama pengamatan yaitu terbang, bersuara dan bertengger pada pohon besar. Hidup berpasangan atau himpunan kecil dengan prilaku umumnya pemalu sehingga sulit untuk mendapatkan fotonya. Burung ini adalah jenis burung pemakan buah lembut seperti pepaya, ficus dan terkadang memakan kumbang atau serangga lainnya.

\section{Gallirallus torquatus (Mandar Padi Zebra)}

Burung Mandar Padi Zebra atau biasa dikenal dengan burung weris saat ditemukan memiki panjang tubuh sekitar $28-33 \mathrm{~cm}$. Pada bagian muka, tenggorokan dan bagian bawah berwarna hitam dengan sebuah setrip putih panjang pada pipi dan bagian bawah berpalang putih (Coates dan Bishop, 1997). Burung ini tersebar di subkawasan Sulawesi dan Kepulauan Sula. Habitatnya biasa umum menghuni padang rumput, sering terdapat di tepian hutan primer dan sekunder yang tinggi, hutan perbukitan, semak campuran, lahan budidaya, sawah-sawah dan mangrove. Burung ini mampu hidup sampai ketinggian 1000 mdpl (Coates dan Bishop, 1997). Pada burung Mandar Padi Zebra aktivitas yang dilakukannya selama pengamatan yaitu berpindah atau bergerak untuk mencari makan. Meskipun tergolong umum dijumpai, namun tidak mudah untuk mendapatkan fotonya Sifatnya yang pemalu adalah sebabnya. Burung ini merupakan pemakan biji-bijian, salah satunya yang paling disukai adalah biji padi.

\section{Ducula aenea (Pergam Hijau)}

Burung Pergam Hijau saat ditemukan memiliki ciri-ciri kepala, leher dan tubuh bagian bawah berwarna abu-abu kemerah jambuan, bagian atas berwarna hijau metalik, tungging coklat tua kemerahan (kadru), serta terdapat bercak pada tengkuk (leher bagian belakang) (Coates and Bishop, 1997; Wantania, 2010). Burung ini sering menghuni di kawasan hutan primer dan hutan sekunder, serta hutan perbukitan. Membandingkan dengan penelitian Wantania (2010) tentang analisis keragaman burung di Gunung Klabat, burung ini ditemukan di hutan sekunder Gunung Klabat. Burung ini mampu hidup sampai ketinggian 1000 mdpl. Aktivitas yang dilakukan burung Pergam Hijau selama 
pengamatan yaitu terbang, bertengger pada salah satu pohon yang tinggi. Burung ini sering bertengger di pohon yang tinggi berpasangan dan mencari makanan. Jenis ini merupakan pemakan buah-buahan kecil dan biji-bijian.

\section{Geopelia striata (Perkutut Jawa)}

Perkutut Jawa saat ditemukan memiliki ciri-ciri ekor yang lebar, agak panjang, Muka putih, kepala berwarna abuabu, leher dan bagian sisi bergaris halus, punggung berwarna coklat dengan tepi hitam. Bulu ekor bagian luar kehitaman, dan berujung putih lebar, dengan panjang tubuh $22 \mathrm{~cm}$ (Coates dan Bishop, 1997). Burung ini lebih sering menghuni pedesaan yang terbuka dengan pepohonan sedikit, perkebunan hutan sekunder dan lahan pertanian. Persebaran burung ini terdapat di Sulawesi, Selayar, Ambon, Maluku, dan NTB (Coates dan Bishop, 1997). Aktivitas jenis burung Perkutut Jawa selama pengamatan yaitu berpindah, terbang dan bertengger. Hidup berpasangan atau dalam kelompok kecil. Makanan utama burung Perkutut Jawa yaitu biji-bijian.

\section{Burung Endemik Sulawesi}

Hasil penelitian yang telah dilakukan di kawasan Hutan Kota Desa Kuwil Kabupaten Minahasa Utara ditemukan 2 burung endemik sulawesi yaitu Kadalan Sulawesi (Phaenicophaeus calyorhynchus) dan Tuwur Sulawesi (Eudynamys melanorhynchus). Tabba et al. (2011) menyatakan Kadalan Sulawesi merupakan afifauna endemik kawasan Sulawesi, jenis ini memiliki tiga sub spesies yaitu calyorhynchus di wilayah daratan Sulawesi Utara, Tengah, Tenggara dan Kepulauan Togian. Sub spesies meridionalis di wilayah Sulawesi Tengah dan Selatan dan rufiloris yang menempati daerah kepulauan Butung. Sedangkan Burung Tuwur
Sulawesi endemik di Pulau Sulawesi dan pulau-pulau sekitarnya (Pulau Talisei, Bangka, Lembeh, Manterawu, Muna, dan Kepulauan Togian), Kepulauan Banggai, dan Kepulauan Sula (Coates dan Bishop, 1997).

Burung Kadalan Sulawesi dan Tuwur Sulawesi bukan merupakan satwa yang terancam. Berdasarkan data International Union Conservation Nation (IUCN) Burung Kadalan Sulawesi dan Tuwur Sulawesi termasuk satwa kategori beresiko rendah, dan di daftar Apendiks CITES tidak mencantumkan kedua burung tersebut. Sehingga tidak banyak informasi dan data terkait jumlah populasi Kadalan Sulawesi dan Tuwur Sulawesi di alam. Meskipun burung ini endemik tetap perlu dilakukan upaya untuk melindunginya. Mengingat pentingnya burung dalam regenerasi hutan dan manfaatnya bagi ekosistem sehingga di masa yang akan datang tidak terancam kepunahan.

\section{KESIMPULAN}

Jenis burung yang ditemukan mencakup 5 bangsa, 8 suku, 10 jenis burung di kawasan Hutan Kota Desa Kuwil Kabupaten Minahasa Utara. Adapun jenisjenisnya adalah sebagai berikut Halcyon chloris, Corvus enca, Pycnonotus aurigaster, Oriolus chinensis, Gerygone sulphurea, Galliralus torquatus, Phaenicophaeus calyorhynchus, Eudynamys melanorhyncus, Geopelia striata, dan Ducula aenea. Indeks keanekaragaman burung sebesar 1,98 yang termasuk dalam kategori keanekaragaman spesies sedang $\left(1,5 \leq \mathrm{H}^{\prime} \leq 3,5\right)$.

\section{SARAN}

Masih perlu dilakukan penelitian lebih lanjut tentang keanekaragaman jenis burung di kawasan Hutan Kota Desa Kuwil Kabupaten Minahasa Utara, terutama tentang aktivitas dan adaptasi jenis-jenis burung yang ada. 


\section{DAFTAR PUSTAKA}

Alikodra, H.S. 1990. Pengelolaan Satwa liar Jilid I. Departeman Pendidikan dan Kebudayaan Direktorat Jendral Pendidikan Tingkat Pusat Antar Universitas Ilmu Hayati Institut Pertanian Bogor, Bogor.

Bibby, C., M. Jones dan S. Marsden. 2000. Teknik-Teknik Ekspedisi Lapangan Survey Burung. BirdLife International Indonesia Programme, Bogor.

Boer, C. 1994. Studi Tentang Keanekaragaman Jenis Burung Berdasarkan Tingkat Pemanfaatan Hutan Hujan Topis di Kalimantan Timur Indonesia. Mulawarman Foresty Reports Faculty of Foresty Mulawarman University IndonesiaGerman Forest Projeck/GT2, Samarinda.

Coates, B. J and D. Bishop. 1997. Panduan Lapangan Burung-Burung di Kawasan Wallacea (Sulawesi, Maluku, dan Nusa Tenggara, Indonesia). Birdlife International Indonesia Programme, Bogor.

Collar, N.J., M.J, Crosby and A.J, Stattersfield. 1994. Birds to Watch 2: The World List of Threatened Birds. Birdlife International, Cambridge.

Dinas Kehutanan Kabupaten Minahasa Utara. 2013. Peraturan Daerah Kabupaten Minahasa Utara Nomor 2 Tahun 2012 Tentang Hutan Kota. http://dishutminut.blogspot.com/20 13/06/peraturan-daerah-kabupatenminahasa.html [01 Oktober 2018].

Ekowati, A., A.D. Setiyani., D.R. Haribowo, dan K. Hidayah. 2016. Keanekaragaman Jenis Burung di Kawasan Telaga Warna, Desa Tugu Utara, Cisarua Bogor. Al-Kauniyah Journal Of Biology. 9(2): 87-94.

Kindangen, N. 2006. Keanekaragaman Jenis Burung di Hutan Gunung Mahawu. [Skripsi]. Jurusan Biologi. Universitas Sam Ratulangi. Manado.
Lee, R.J., J. Riley and R. Merril. 2001. Keanekaragaman Hayati dan Konservasi di Sulawesi Bagian Utara. Wildlife Conservation Society \& Natural Resource Management Program, Jakarta.

Oktiana, D., dan W. Antono. 2015. Keanekaragaman burung di lingkungan Unit Pembangkit Indonesia Power (UP IP) Tambak Lorok, Semarang. Pros Sem Nas Masy Biodiv Indon. 1(5): 1045-1049.

Patandung, A., J.S. Tasirin., A. Thomas, dan R.P. Kainde. 2014. Struktur Dan Komposisi Jenis Komunitas Burung di Lahan Pertanian Kawasan Hutan Lindung Gunung Mahawu Sulawesi Utara. COCOS. 4(5): 44-48.

Sukmantoro. W., M. Irham., W. Novarino., F. Hasudungan., N. Kemp, dan M. Muchtar. 2007. Daftar Burung Indonesia No.2. Indonesian Ornithologist's Union, Bogor.

Tabba, S., D.I.D Arini, dan S. Shabri. 2011. Asosiasi Burung Kadalan Sulawesi (Phaenicophaeus calyorhynchus) dengan Monyet Primata Sulawesi. Balai Penelitian Kehutanan, Manado.

Tallei, T.E., Saroyo, and V.R. Tallei. 2018. Wild Birds Diversity in Mount Tumpa Forest Park North Sulawesi Indonesia. Bioscience Research. 15(1): 443-452.

Wantania, F. 2010. Analisis Keragaman Burung di Gunung Klabat. [Skripsi]. Jurusan Biologi. Universitas Sam Ratulangi. Manado

Widodo, W. 2009. Komparasi Keragaman Jenis Burung-Burung di Taman Nasional Baluran dan Alas Purwo Pada Beberapa Tipe Habitat. Jurnal Berkala Penelitian Hayati. 4(1): 113-124. 